\title{
PROCESSOS CIVILIZADORES NAS REDES SOCIAIS E A GORDOFOBIA
}

\author{
Carolina dos Santos Jesuino da Natividade iD1 e Célio Juvenal Costa (D2
}

\section{Resumo}

O presente trabalho acompanha como a trama da atual figuração caminha para aumentar o autocontrole nas redes sociais especificamente contra expressões de preconceito sobre pessoas obesas. Um dos objetivos do estudo é descrever brevemente a condição de obesidade, que suscita fortes pressões contrárias de motivações biomédicas e ético-morais que também servem de justificativa para o preconceito denominado de gordofobia. Busca-se caracterizar a gordofobia, assim como a crescente punição dada nas redes sociais a atos preconceituosos como na cultura de cancelamento e descrever as políticas das redes sociais como manuais de conduta para seus usuários, nos quais proíbe humilhações e rebaixamento de indivíduos/grupos por suas características de minorias. $\mathrm{A}$ pesquisa procedeu-se com levantamento bibliográfico sobre a condição de obesidade e gordofobia, posteriormente caracterizou-se a cultura de cancelamento como forma de punição do usuário e as regras das redes sociais Facebook, Youtube e Twitter sobre limites para a expressão como um manual de conduta. É utilizado o referencial de Norbert Elias para interpretar os manuais das plataformas digitais como processos civilizadores. Obteve-se que embora as referidas redes não façam menção à gordofobia, o movimento de maior conscientização e empatia sobre a obesidade, aliado a consequências econômicas e sociais para ações preconceituosas, indica que pode haver inclusão nos regulamentos, resultando em maior pressão sobre o autocontrole de expressões gordofóbicas.

Palavras-chave: Evolução dos costumes; Redes sociais; Preconceito; Minorias; Manuais de conduta.

\section{CIVILIZING PROCESSES IN SOCIAL NETWORKS AND FATPHOBIA}

\section{Abstract}

This study demonstrates how the current figuration is increasing self-control in social networks against expressions of prejudice about obese people. The study describes the condition of obesity, which arouses contrary pressures of biomedical and ethical-moral motivations. The obesity serves as a justification for the prejudice called fatphobia. We seek to characterize fatphobia and the growing punishment given in social networks to prejudiced acts, as in the culture

\footnotetext{
${ }^{1}$ Mestre em psicologia pela Universidade Federal de Mato Grosso do Sul (UFMS). Professora da Fundação Educacional Jandaia do Sul (FAFIJAN).

${ }^{2}$ Doutor em educação pela Universidade Metodista de Piracicaba e professor na Universidade Estadual de Maringá. 
of cancelation. We pretend to describe policies of social networks as manuals of conduct for its users, in which it prohibits humiliations and demeaning to individuals/groups and their minority characteristics. The research proceeded with a bibliographic survey on obesity and fatphobia conditions, characterized the culture of cancelation as a form of punishment to user, and the rules of social networks as Facebook, YouTube and Twitter on limits to expression as a manual of conduct. Norbert Elias' referential are used to interpret the manuals of digital platforms as civilizing processes. It was obtained that although the networks do not make mention of fatphobia, the movement of greater awareness and empathy of obesity, combined with economic and social consequences for prejudiced actions, indicates an inclusion in the regulations, resulting in greater pressure on self-control of fatphobic expressions.

Keywords: Habits Evolution; Social Medias; Prejudice; Minorities; Conduct Manuals.

\section{Introdução}

As ideias dos processos civilizadores, ocorrido principalmente no século XVII na Europa, como descrito por Elias (2011, b) podem ser aplicadas para eventos tanto observados na atualidade quanto a regulação de comportamentos que se dão nas redes sociais sobre preconceitos contra pessoas obesas. As observações dos manuais de etiqueta que circulavam nas cortes europeias foram as fontes utilizadas por Elias em sua análise socio e psicogenética sobre o maior autocontrole que a figuração cortesã da época do absolutismo requereu. As interações da vida cortesã resultaram em uma certa padronização da menor demonstração de emoção de modo impulsivo e espontâneo. As consequências muito impactantes da demonstração das verdadeiras emoções e comportamentos de apreço e desapreço poderiam levar um nobre a ruína. Como a nobreza já era alfabetizada, começaram a ser muito consumidos por ela manuais de etiqueta para que passassem a conduzir seu comportamento de modo mais distante da real emoção despertada por um evento. Com a formalização das ações e reações houve maior padronização do autocontrole individual. Como aponta Elias $(2011$, b), a civilização ocidental em seu estado atual não surgiu do modo como é encontrada, pois passou por processos lentos de transformação. O que o sociólogo expõe é que a total falta de limites nas trocas interpessoais foi substituída por progressivo aumento de regras que limitam a liberdade de expressão.

Atualmente, nos meios digitais, observa-se semelhante regulação das emoções. A comunicação mediada pela internet deixa de ser uma terra sem lei quanto a atitudes que rebaixem algum indivíduo ou grupo por suas características menos valorizadas socialmente. Esse maior cuidado com a comunicação também tem se expandido para a população obesa. Na atualidade, muitas minorias lutam para receber tratamento respeitoso. Há forte movimento de mulheres, inclusive de mulheres negras, coletivos contra o racismo, contra preconceito sobre população LGBTQIA+ entre outras. O movimento contra esse 
preconceito criou um nome específico para ele: gordofobia, que se manifesta com piadas e/ou expressões verbais que ridicularizem a pessoa obesa por essa característica. Os efeitos desses atos podem ser de humilhação, medo e vergonha de sair de casa, deixar de fazer o que gosta e de ir a lugares, baixa autoestima e depressão.

As redes sociais de grande abrangência têm, em suas plataformas, regras de condutas claras sobre discriminação para várias minorias, sendo que algumas delas são designadas como categorias protegidas, cujo cuidado na expressão de opiniões sobre elas é muito enfatizado em suas diretrizes. Isso significa que a conduta regulada e autorregulada quanto a minorias nas principais redes sociais seria um indício de como manuais de conduta nas redes sociais indicariam processos civilizadores em jogo. Em relação à gordofobia, sua não inclusão nas categorias de proteção leva a crer estar diante de um grupo que poderá ter direito a pertencer aos grupos minoritários, pois os movimentos contra tal preconceito aumentam, punindo de modo mais enfático e sistemático falas desrespeitosas.

\section{Metodologia}

Ao descrever a metodologia para demonstrar os processos civilizadores, Elias afirma que "[...] só vemos o mecanismo de padronização em sua sequência, se examinarmos como um todo a série de imagens." (ELIAS, 2011, b, p. 112). Ou seja, pela observação dos manuais de conduta social pode-se sinalizar mudanças no modo como cada indivíduo deveria se autocontrolar quando em grupo para obter os melhores recursos.

Reconhecendo que em momentos de grande mudança social há inovações nos costumes, é possível transpor a lógica de análise eliasiana aplicada no entendimento dos manuais de conduta das Sociedades de Corte absolutistas para as interações entre homens e mulheres nas redes sociais diante de restrições de manifestações gordofóbicas. Com a observação de manuais de conduta em redes sociais se pode notar mudanças na expressão de comunicações mediadas pela internet que regulam os comportamentos para que haja maior respeito às minorias. Sobre as mudanças sociais, Elias (2011, b) avisa que os movimentos históricos não são retilíneos, mas permitem ver tendências globais, que nesse estudo acredita-se haver evidencias de ser um momento de transição de um momento pouco regulado e civilizado sobre o preconceito contra pessoas obesas para um período mais regulado. Embora existam várias redes sociais, foram selecionadas três devido a sua repercussão mundial: Youtube, Facebook e Twitter, sendo seus manuais de conduta de seus usuários analisados.

\section{Resultados e discussões}

A justificativa dessa explanação usa dos argumentos de Ribeiro (2014), pois a modificação das atitudes frente a pessoas obesas se trata de amplitude do pensamento de Elias, algo bastante recorrente entre os autores que exploram 
sua categoria do processo civilizador, com cada leitura se tratando de interpretação sobre o sociólogo. Isso porque o aporte analítico de Elias sobre os processos não foi planejado para tratar especificamente do tensionamento das relações de preconceito a um grupo de pessoas, como o sobre pessoas obesas. É necessário reforçar que os processos tensos de controle das emoções não ocorrem de forma linear, portanto, há embates entre aqueles que se encontram no polo opressor e oprimido, contudo várias minorias têm conseguido judicialmente e por pressão popular ter seu direito à dignidade recuperado, indicando uma progressiva diminuição da agressividade verbal anteriormente praticada sem limitações. (RIBEIRO, 2014).

Descrever o preconceito contra pessoas obesas é estar no limite entre o que é consequência de escolhas individuais e aspectos ambientais que favorecem a maior expressão dessa condição. Este trabalho não pretende discorrer sobre a psicogênese e sociogênese da obesidade, contudo é importante situar os fatores sociais para que se possa entender que a mesma sociedade que gera a condição de obesidade a condena como se se tratasse apenas do uso de liberdade de escolha de cada indivíduo. Na atual figuração, a obesidade gera muitas implicações na vida das pessoas, seja emocional seja interpessoal. Os novos hábitos adquiridos com a grande industrialização de alimentos, propagandas de alimentos calóricos e o estilo de vida mais sedentário são as razões ambientais envolvidas para o maior número de obesidade no mundo. "Acredita-se que tais mudanças na alimentação e hábitos de vida sedentários atuando sobre os genes de suscetibilidade sejam o determinante principal do aumento da obesidade no mundo." (XIMENES; XIMENES; LINS, 2009, p. 20).

De modo objetivo, a obesidade é caracterizada pela Associação Brasileira para Estudos da Obesidade e Síndrome Metabólica- ABESO (2009) pelo excesso relativo ou absoluto de gordura corporal, provocado por desequilíbrio nutricional associado ou não a distúrbios genéticos ou endócrino-metabólicos. O diagnóstico de obesidade depende predominantemente do cálculo do Índice de Massa Corpórea-IMC, que também é usado na avaliação da distribuição e quantificação de gordura. No estudo do Ministério da Saúde intitulado "Estratégias para o cuidado da pessoa com doença crônica: obesidade" (BRASIL, 2014) aponta outros recursos para a avaliação quando o IMC é maior ou igual a 25, como a avaliação de circunferência, lipidograma, pressão arterial, glicemia, avaliação do risco cardiovascular e risco de condições endócrinas. Contudo, diariamente não se recorre à definição formal de obesidade para que se atribua tal característica. De modo prático e subjetivo, é a maior ou menor aproximação com um estereótipo de distribuição de massa gorda que gera o rótulo de obeso/a.

A discriminação e o preconceito intensificam problemas psicológicos e sociais de pessoas obesas. Em Myers (2014), lê-se que o preconceito é um julgamento negativo preconcebido sobre um grupo ou indivíduos, marcado por avaliações negativas, chamadas de estereótipos. Os estereótipos são generalizações, o problema é quando eles são excessivamente generalizados ou errados. Uma vez formados eles tendem a se perpetuar e resistir a mudanças. Há muitos estereótipos sobre a obesidade, alguns deles baseados em uma visão biomédica. Conforme apontam Paim; Kovaleski (2020) anormal é ter o corpo 
gordo, ideal cuja difusão apresenta o risco de se transformar num instrumento de norma médica. Dessa forma a existência de corpos gordos é vivido pelas pessoas como uma doença, deixando de ser apenas um atributo físico. Segundo Poulain (2013), a obesidade é encarada como uma questão de saúde, gerando um preconceito muito aceito devido ao discurso médico que o legitima. Ao tratar da sociologia da obesidade, Poulain (2013) afirma que é um fenômeno muito complexo por ser considerada problema de saúde pública e de estigmatização. O aspecto de saúde pública surgiu quando a Organização Mundial de Saúde-OMS passou a considerá-la como epidemia mundial.

É possível problematizar a conceitualização médica de obesidade, porque na opinião de Paim; Kovaleski, (2020, p. 4, grifo nosso): "A obesidade é definida de forma simplista pela OMS como o acúmulo anormal ou excessivo de gordura corporal, que afeta e prejudica a saúde.". Conforme Poulain (2013), a obesidade foi oficialmente integrada à Classificação Internacional de Doenças-CID em 1990. Antes era considerada um fator de risco, porque ninguém morre de obesidade, porem de doenças favorecidas por ela. Autores como Ximenes; Ximenes; Lins (2009) conceituam a obesidade como doença crônica caracterizada pelo acúmulo de adiposidade, contudo não há um consenso se é uma doença ou uma condição que favorece o aparecimento de doenças. Problematiza-se, também, a relação obesidade-doença e magreza-saúde, pois Sobczak (2014) aponta que não se pode assumir que uma pessoa obesa seja sempre doente e que uma pessoa magra seja sempre saudável.

As opiniões médicas convergem quanto ao risco da obesidade elevar os riscos para a saúde devido a sua relação com várias complicações metabólicas. Se há evidências de aumento de risco de doenças quando há obesidade, não há a mesma quantidade de indícios na condição de sobrepeso. Contudo, há um forte discurso contra a obesidade e contra o sobrepeso, como indicam Paim; Kovaleski (2020, p. 5): "Atualmente, tem-se outorgado o direito de intervenção ao sobrepeso munido do discurso do risco, tomando o risco como uma categoria de pré-doença - até porque o sobrepeso já é considerado uma forma de préobesidade.".

Para Rigo; Santolin (2012), a obesidade é considerada oficialmente uma doença para a classe médica. Já Paim; Kovaleski (2020) defendem que tal discurso tem se generalizado para qualquer sobrepeso, tornando o que se desvia da magreza uma situação digna de suspeita. A motivação de ir contra a obesidade é declarada por Paim; Kovaleski (2020, p. 4), pois: "O discurso científico aborda a obesidade como uma doença e formaliza o emagrecimento como uma questão de saúde. Por esse viés, a área da saúde declara guerra contra a obesidade e a justifica pela aparente preocupação com a saúde da população.".

A perseguição à obesidade como doença de modo estigmatizante foi apontado por Paim; Kovaleski (2020) como presente no documento publicado pela ABESO, que divulgou, em 2009, as Diretrizes Brasileiras de Obesidade, que apresenta relato genérico sobre o IMC acima de 30 aumentar risco de surgimento de doenças crônicas sem citar quais e sem fazer o contraponto de 
que o IMC abaixo de 18.5, baixo peso, também levar a amplo leque de doenças como osteoporose, desnutrição, prejudicar desenvolvimento físico e cognitivo, favorecer doenças infectocontagiosas e degenerativas e limitar a capacidade física. A "caça às bruxas" fica evidente ao se falar apenas dos riscos da obesidade sem considerar os do outro extremo alimentar, como se apenas um dos extremos fosse danoso passando a mensagem de que quanto mais magro menos riscos à saúde. Paim; Kovaleski (2020) discorrem que de acordo com documentos da ABESO, o sobrepeso, como condição pré-doença, recebe o alarme de situação perigosa e que deve ser evitada, levando o discurso biomédico à estigmatização do sobrepeso tal qual da obesidade, embora tal relação entre sobrepeso e adoecimento não esteja demonstrada. Com esse discurso, expressões gordofóbicas são direcionadas não só a pessoas obesas, quanto a pessoas com um mínimo de sobrepeso.

Em contra partida, interessante provocação é feita por Chaput; Doucet; Tremblay (2012) a respeito da obesidade ser uma doença ou uma questão de adaptação biológica a um ambiente de abundância de comida, posto que a atualidade é de estresse crônico, baixa atividade física e excesso de comida. Vive-se em um ambiente facilitador da perda de controle alimentar, o que favorece o sobrepeso e a obesidade.

Além do discurso biomédico, o preconceito também é baseado em visão ético moral contra a obesidade, pois conforme Paim; Kovaleski (2020, p. 5) o indivíduo que não é magro é visto como um custo para a comunidade: "Quando o indivíduo não alcança e ameaça o tipo ideal de corpo, sua atitude é entendida como negligência e é produzida uma forte exclusão social em relação aos corpos gordos, que são discriminados, rejeitados e culpabilizados.". Enquanto Rigo; Santolin (2012) falam em discursos biomédicos morais, espalhados pelo corpo social, Paim; Kovaleski (2020, p. 6) acrescentam que: "As políticas públicas partem do pressuposto de que as pessoas com excesso de peso subestimam seu peso e, portanto, que identificar-se seria um requisito para o sucesso da gestão do próprio peso.". Sobre o impacto coletivo da obesidade nos sistemas de saúde, Rigo; Santolin (2012, p. 282) alertam:

Com intuito de contornar essa esfera individual, muitos estudos sobre o assunto trazem os prejuízos financeiros causados pela obesidade e o impacto orçamentário na saúde pública. [...] A incitação do medo provocada pelo conceito de risco associado a uma noção moral, puramente abstrata, de qualidade e expectativa de vida ajuda a forjar no corpo social a verdade de que os obesos não somente são doentes, mas que eles têm a obrigação de emagrecer, inclusive pelos prejuízos que, supostamente, acarretariam aos cofres públicos. (RIGO; SANTOLIN, 2012, p. 282).

Falar dos custos da obesidade para a saúde pública é aliar a motivação médica à moral. Acentuando a relação entre o discurso biomédico e o éticomoral, Rigo; Santolin (2012, p. 283) expõem: 
Na atualidade, a partir de uma classificação das biociências, que colocam a obesidade como doença, o tema tornou-se palco de inúmeras controvérsias éticas e políticas, que vão desde campanhas que reivindicam direitos básicos de cidadania até a denúncia de violência (bullying), preconceito, estigmatização e segregação social. (RIGO; SANTOLIN, 2012, p. 283).

Todas as justificativas para atacar a condição de obesidade quando passam do razoável e atingem um indivíduo ou grupo podem ser indicativas de ódio ou aversão chamada de gordofobia. Segundo Rangel (2018, p. 19), a gordofobia: "[...] é utilizada para denominar o preconceito, estigmatização e aversão englobados por meio de uma opressão estrutural na sociedade que atinge as pessoas gordas.". A inquestionabilidade da saúde das pessoas magras é um exemplo de gordofobia, pois estas acabam vivendo em situação de privilégio e, mesmo que de forma involuntária e inconsciente, beneficiam-se dessa opressão, embora a gordofobia ainda nem seja reconhecida enquanto uma opressão (PAIM, KOVALESKI.2020).

A literatura internacional tem demonstrado a relevância dos efeitos de gordofobia na saúde física e mental das pessoas. Uma pesquisa nos EUA demonstrou objetivamente os efeitos deletérios da gordofobia de médicos sobre o acompanhamento clínico de indivíduos obesos. Østbye (2005) contou com dados de 8,4 mil mulheres acima de 50 anos, indicando que quanto maior o IMC, menor foi a prevalência e indicação de exames preventivos, como papanicolau e mamografia. Enquanto $71 \%$ das mulheres com peso considerado normal tinham feito papanicolau nos últimos dois anos, o percentual caía para $57 \%$ em mulheres consideradas obesas. O mesmo foi observado com mamografia, exame feito por $74 \%$ das mulheres com peso normal e $68 \%$ das obesas. Os números ressaltam que não é a obesidade que aumentou o risco de adoecimento para pessoas obesas, mas a conduta médica de focar na obesidade como doença e não lidar com um ser humano integral. Como se diante da obesidade outras necessidades, biológicas inclusive, ficassem invisíveis para os profissionais responsáveis pela saúde. Aliado a essa evidencia cientifica do dano da gordofobia a saúde, outros casos são denunciados ao público em notícias sobre a não investigação clínica de problemas de saúde em situação de queixa pelo paciente obeso, que apenas recebeu orientação médica de emagrecimento, só chegando ao diagnóstico de câncer quando em fase terminal em uma senhora de 64 anos no Canadá, de acordo com Lira (2019). Mulheres obesas são vítimas mais contumazes de violência obstétrica, desde o momento em que buscam por acompanhamento gestacional, recebendo recusas sob a justificativa de maior risco, quanto ofensas e comentários agressivos no momento do parto. (MELERO, 2020).

Melo, Farias e Kovacs (2017) afirmam que há um estigma da obesidade como um problema de gula, desleixo e/ ou preguiça. Os estereótipos criados pela figura do gordo nasceram ao longo de muitos anos, de doente passa a relaxado, atrapalhado, incapaz de alcançar o corpo ideal. Enquanto estigmatizadora, a obesidade produz discriminação, preconceito e exclusão 
social do indivíduo. Conforme Melo, Farias e Kovacs (2017, p. 306), "A cultura ocidental valoriza a magreza embasada principalmente pelas descobertas da biomedicina, que transformou o corpo gordo em sinônimo não apenas de falta de saúde, mas em um 'corpo desumanizado'; um caráter pejorativo de falência moral.".

Outros efeitos desse preconceito são descritos no estudo de Vartanian e Shaprow (2008), que investigou a relação entre o estígma de peso, motivação para fazer exercício e o fazer exercício. Contando com cem universitárias com IMC entre 17 a 38 obteve que quanto maior o estígma maior o IMC e a insatisfação corporal. Outra correlação obtida foi entre maior estígma e maior desejo em evitar fazer exercícios. Tais dados sugerem que o estígma de peso pode diminuir os níveis de atividade física. Já no estudo de Latner et al (2009) encontrou-se dados de que os participantes de um tratamento da obesidade com experiencias mais estigmatizantes e IMC mais altos se correlacionaram com maior chance de se manter no peso depois de seis meses do tratamento.

De modo mais pessoal, a jornalista e ativista do movimento antigordofobia, Gurgel (2018) fala em primeira pessoa das consequências na saúde física e mental dos atos preconceituosos que passou desde sua infância. A escritora e youtuber narra que o preconceito social faz com que uma pessoa gorda não queira ser ela própria, pois sempre passa-se a ideia de que antes de ter prazer com a própria vida, deve-se estar nas medidas consideradas adequadas. O que gera ódio contra si mesma frente ao discurso da pessoa obesa como alguém que falhou. Gurgel (2018) conta que apesar de muito comunicativa, o preconceito contra seu corpo a mantinha afastada de novas amizades, relacionamentos e descobertas. Outro relato é dado por Tovar (2018), no qual a autora ressalta o quão doloroso era a sensação de falha pelo corpo que tem e o senso de dever em consertá-lo, tornando-o magro. O valor pessoal dependia do tamanho de seu corpo. Somente quando adulta pode entender que seu sofrimento se deve a uma série de eventos violentos e culturalmente sancionados pelos quais passou.

Diante de grande desvalorização social, formou-se um movimento de enfrentamento ao preconceito contra pessoas gordas, contra a gordofobia, que é entendida por Melero (2020) como preconceito a corpos gordos, uma aversão a quem apresenta sobrepeso ou obesidade. O movimento usa a internet para diminuir o estigma, como narra uma das administradoras do site Stop gordofobia, Piñeyro Bruschi (2016), grupos de pessoas e páginas da internet debatem e investigam formas de combater a gordofobia. Tal militância se dá principalmente pelas redes sociais e sites. Interessante ponto é destacado por Piñeyro Bruschi (2016, p. 14-15, tradução nossa) sobre o comportamento na internet: "Não entendo como trivial o fato do protesto ter surgido na rede [social] sob a possibilidade de anonimato e da liberdade que ele proporciona ao relatar abertamente a discriminação, para expor nossa privacidade ao contar histórias pessoais de humilhação" (PIÑEYRO BRUSCHI, 2016, p. 14-15).

As redes sociais têm sido palco de diversos confrontos ideológicos entre aqueles que acreditam favorecer o emagrecimento ao difamar e rebaixar as 
pessoas obesas (que assim passariam a se motivar a caber dentro dos padrões morais de saúde e estética) e aqueles que veem a obesidade como uma condição de difícil modificação e que deve suscitar respeito.

E a análise de Elias sobre a sociedade de corte na França absolutista, como se encaixa nessa discussão? É válido lembrar o contexto social, econômico e político dessa época, para poder responder à questão. Nas interações ocorridas na corte francesa de Luiz XIV, o modo de lidar da aristocracia entre si era um fator que revelava o valor de um indivíduo dentro daquela figuração especifica. A cortesia dispendida a um sujeito estava ligada ao quanto de favorecimento recebia do rei, um aspecto rapidamente mutável e instável de sua valorização social, juntamente com sua representação na sociedade quanto a merecer o título de nobreza sustentado por sua casa. Para que dispusesse de capital para ostentar o seu luxo, havendo a proibição de angariar riqueza tal qual a burguesia, o apreço real era um fator determinante para que a casa de um nobre continuasse a gastar de modo pródigo e manter-se em sua posição. Honrar seu ethos requeria gastos constantes, o que dilapidava sua riqueza. Quando no auge de gastos e de favorecimento real, o nobre recebia tratamento extremamente cortês, contudo ao decair o gasto e favorecimento, o refinamento era substituído por algum nível de ostracismo. A figuração, tal qual um jogo de cartas, sugeria que se conhecesse bem o status de um indivíduo quanto aos seus gastos exorbitantes e agrado de rei (tal como se busca entender as cartas de um jogador pelas jogadas que faz) como parte de sua estratégia para saber quanto apreço e frivolidades trata-lo. A etiqueta, o que dizer e que sentimentos esconder eram aspectos fundamentais para se manter o status. As interações entre membros da corte e entre estes e o rei no período absolutista da França eram extremamente calculadas, não havendo espaço para demonstrações impulsivas de sentimentos sem risco de grave punição. (ELIAS, 2011a).

O autocontrole não afetava apenas a vida social do nobre, mas sua posição na corte. Demonstrar etiqueta não era algo frívolo, a deferência manifestada tratava-se de documentação literal do lugar que o indivíduo ocupava. A perda de hierarquia para o cortesão gerava um impacto similar ao de um comerciante que perde seu capital. Ser aristocrata era estar sujeito a pressão das opiniões para confirmar seu prestígio. Sem a confirmação do prestígio por meio do comportamento dos outros esse destaque não produzia a manutenção de seu status. (ELIAS, 2011, a).

Elias $(2011$, a) estudou relações face a face que ocorriam nas cortes, já a atual investigação propõe analisar tipos específicos de interações que ocorrem de modo assíncrono e em meio digital, chamada de comunicação mediadas pelo computador (CMC), considerando que muito da espontaneidade pode gerar consequências desastrosas nos meios tecnológicos e, por tanto, também na vida offline. Recueiro (2014) explica que as trocas que acontecem entre falantes são adaptadas para ferramentas primariamente textuais, muitas vezes assíncronas, por meio da criação de convenções e novos sentidos entre os atores. A similaridade funcional entre trocas offline e online é explicada, pois; "Dizemos que a conversação mediada pelo computador é, assim, uma apropriação, ou seja, uma adaptação de meios que originalmente são textuais e não propícios 
às interações orais para um fim, que é aquele da conversação." (RECUEIRO, 2014 , p. 115). As interações mediadas pelas tecnologias de comunicação são frequentes, intensas e afetam a vida emocional, financeira, social dos indivíduos. Mesmo pessoas que nunca tenham se encontrado fisicamente podem afetar e serem afetadas intensamente pelas CMC, porque é muito mais do que uma simples conversa dada a partir da mediação de uma ferramenta tecnológica. Ela tem se mostrado como um meio alternativo de expressar valores e crenças coletivas que nem sempre são manifestados fora do contexto digital. É possível dizer que a CMC influencia na construção das relações sociais, tanto positiva quanto negativa. A expressão de ódio e preconceitos é um dos aspectos que suscitam maiores reações dos usuários das redes sociais. Embora haja muitas manifestações de diversos tipos de preconceito nas redes sociais que nem sempre são admitidas como danosas pelos seus administradores (com a exclusão da postagem ou suspensão da conta- isto é, o direito de participar da rede), o comportamento do usuário pode punir comentários racistas, classistas, machistas, xenofóbicos ou gordofóbicos. A punição nos meios virtuais pode ocorrer na forma do que foi cunhado de cultura de cancelamento.

O cancelamento digital ocorre nas principais redes sociais e sua cultura é explicada por Sanches (2020), haja vista que começou há alguns anos como uma forma de chamar a atenção para causas como justiça social e preservação ambiental. Apareceu como uma maneira de amplificar a voz de grupos oprimidos e forçar ações políticas de marcas ou figuras públicas. Seu funcionamento pode iniciar com um único usuário de mídias sociais, como Twitter e Facebook, que presencia uma situação que considera errada, registra e posta em sua conta, marcando a empresa empregadora do denunciado e autoridades públicas ou outros influenciadores digitais que possam ampliar o alcance da mensagem. Em questão de horas, o post é replicado milhares de vezes. A própria cultura do cancelamento suscita um olhar eliasiano, como discorre Costa (2013, p. 159160): O comportamento individual, próprio de uma ou mais gerações, não tem explicação nele mesmo, ou seja, um determinado comportamento, quando se generaliza na sociedade, é explicado justamente pelos fundamentos sociais, econômicos e culturais da própria sociedade.

De modo resumido, o cancelamento é um ataque à reputação que ameaça o emprego e os meios de subsistência atuais e futuros do cancelado, abate personalidades conhecidas e também anônimos fazendo apelo à vergonha pública e ao ostracismo. As ações que levam ao cancelamento podem ocorrer no mundo offline ou online, contudo os comportamentos gordofóbicos mais facilmente identificáveis e registráveis são em formato de posts. Em charges e comentários ofensivos com ou sem imagens, o preconceito destilado é muito mais perceptível e inegável.

Diante do exposto sobre a crescente regulação das emoções nas CMC, desponta a necessidade de regras de convivência nos meios digitais, cabendo falar de processos civilizadores ocorrendo na forma de manuais específicos para os meios digitais como os chamados de netiqueta. Se na convivência corpo a corpo há a etiqueta, no meio virtual existe a netiqueta, um neologismo que mistura as palavras internet e etiqueta. Para Ivo (2017), netiqueta é definida 
como um conjunto de regras básicas que guiam a boa convivência das pessoas na internet. Ela ajuda a evitar o surgimento de ruídos e falhas nas comunicações devido a deslizes que se comete, às vezes até por falta de conhecimento, sobre como se comportar. Os manuais de netiqueta ainda não são claros quanto a como se portar diante de minorias, contudo há um consenso de que se deve respeitar os direitos humanos em comentários e discussões. Novos hábitos online vêm se normalizando, pois desrespeito online pode se transformar em transtornos offline, como a cultura do cancelamento demonstra.

A netiqueta apareceu primeiro nas empresas e em instituições de ensino remoto, para regular interações entre discentes nos chats em que manifestavam suas opiniões sobre os conteúdos estudados. Como a interação humana facilmente pode caminhar para agressões verbais, tão rápido quanto surgiu a netiqueta para o contexto específico de profissionais em seu ambiente fechado de trabalho e de alunos em cursos à distância, ela se mostrou útil em vários contextos de manifestação de expressões, como nas diversas redes sociais. Embora a rede social Facebook não faça uso do termo netiqueta, ela criou uma espécie de manual de boa convivência na qual regula excessos e indica de que modo seus usuários podem manifestar-se livremente, mas garantindo integridade a várias características protegidas, que são raça, etnia, nacionalidade, religião, orientação sexual, casta, sexo, identidade de gênero, doença grave ou deficiência. Esse manual proíbe e define ataques como discursos violentos ou degradantes, estereótipos prejudiciais, declarações de inferioridade, expressões de desprezo, xingamentos e ordem de exclusão. Várias sutilezas para manter a liberdade em meio à proteção são descritas, como proteger o migrante, embora se possa criticar a política de migração. (FACEBOOK, 2021).

Para que as pessoas possam se comunicar mais livremente, o Facebook busca criar um ambiente sem intimidação e exclusão. Os ataques e discursos de ódio que a plataforma proíbe são declarações ofensivas as características protegidas. Como pessoas com obesidade sofrem ataques que os depreciam, podem ter de recorrer a denúncias para coibir falas ofensivas, pois ainda se está educando a população sobre gordofobia. O que não se deve dizer a característica protegida ou semiprotegida é compará-las a insetos, seres sub-humanos e criminosos. (FACEBOOK, 2021).

Embora cada plataforma crie seu manual de conduta, muitos manuais informais são encontrados em outros sites indicando os comportamentos mais esperados nessas plataformas. Mesmo que as plataformas não sejam locais com a finalidade única de gerar relações profissionais, promoções e mudanças na carreira, determinados posicionamentos e conteúdos podem levar a modificações drásticas no modo de trabalho, positiva ou negativamente. Também podem afetar a vida em família e em comunidade. Interessante que nos manuais mais informais redigidos por um único autor, talvez por isso mais diretos, há ainda a regulação de aspectos ligados a fisiologia. Não é mais preciso avisar sobre não soltar gazes em público, porém deve-se orientar que não é preciso descrever a intimidade dos fenômenos fisiológicos no Facebook, como afirma Marquezi (2012), porque poucas pessoas teriam real interesse em 
assuntos tão particulares e as redes sociais são poderosos instrumentos de comunicação.

O mesmo comentador de comportamentos dessa plataforma diz que uso de acentos, pontos, maiúsculas e minúsculas de modo correto é como comer com garfo e faca e não cuspir farofa, ou seja, o mínimo exigido. Outra comparação da vida online com a offline é de que não se use posts públicos para conversas particulares, como convidar alguém para jantar, pois combinar encontro pelo feed do Facebook seria como conversar sobre intimidades no vivavoz do escritório, uma falta de bom senso. Uma orientação bastante relevante para não incidir em ato gordofóbicos é ter consciência de que os pensamentos no Facebook tendem a ser superficiais. E se espalham com enorme velocidade. Uma opinião tem consequências, o que exige conhecimento, reflexão e objetividade.

Outra plataforma que reúne milhares de pessoas por meio de vídeos e trocas por meio de comentários aos vídeos e a outras falas é o Youtube. Com a missão de propiciar que todos possam fazer e divulgar vídeos, nessa rede social elementos de comunicação oral e escrita interagem. Com tamanho potencial de comunicação, muitos profissionais dedicados a essa plataforma criam conteúdos educacionais, cômicos e instrucionais. Como em qualquer reunião de pessoas pode haver excessos, para impedir atos de violência o Youtube explica suas diretrizes para coibir condutas violentas contra certos grupos, suas categorias protegidas: idade, classe social, deficiência, etnia, identidade e expressão de gênero, nacionalidade, raça, situação de imigração, religião, gênero, orientação sexual, vítimas de evento violento e veteranos de guerra. Nesse manual, a rede explicita que vídeos ou comentários ofensivos a tais categorias podem levar à denúncia do canal. (YOUTUBE, 2021).

Já no Twitter, nos 140 caracteres permitidos para postagens, a mensagem não deve conter incitação de violência, atacar diretamente ou ameaçar membros das seguintes categorias: raça, etnia, origem nacional, orientação sexual, sexo, identidade de gênero, religião, idade e deficiência ou doença grave. (TWITTER, 2021). Sobre o uso da netiqueta no Twitter, seja para adquirir popularidade, seja para ser visto e lembrado, Panissi (2009) aconselha que há algumas regras como aceitar que Twitter não é chat ou comunicador instantâneo. O principal objetivo da ferramenta é a divulgação de ideias por meio de frases curtas e links. O serviço tem meios de interação entre seus usuários que devem ser usados com cuidado. Sobre o modo de se apresentar, na foto que aparece do lado do perfil, a imagem escolhida irá mostrar aos seguidores como você quer ser visto, e uma escolha errada pode comprometer negativamente.

O próprio tom das orientações de uso do Twitter dado por Panissi (2009) é de um usuário mais experiente para os neófilos, quando indica que a pergunta padrão exibida na interface do Twitter deve ser entendida com parcimônia, porque digitar tudo o que se faz a todo momento passa a ser chato. A plataforma torna-se relevante quando as pessoas dizem coisas interessantes. 
Mesmo que nos documentos que consta nessas redes sociais não façam menção explicita a gordofobia, prevêm que a rede não deverá ser usada para atacar algum indivíduo ou grupo minoritário. Tal baixa expressão de reconhecimento desse movimento é também notado com a pouca produção acadêmica sobre gordofobia. Contudo, em sites pessoais, canais de Youtube e livros escritos por quem sofreu o preconceito proliferam discussões sobre 0 tema, indicando fortalecimento do movimento que clama por respeito. Tal qual na figuração das sociedades de corte, os comportamentos na internet não são somente motivo de punição com o cancelamento (praticado por usuários) ou perda da conta/perfil/canal (efetuado pelas plataformas). A internet é campo no qual também se enaltece aqueles que se destacam por suas opiniões e posicionamentos. A visitação de um perfil ou canal gera renda, portanto, quanto maior o apreço recebido maior status e renda. Situação que lembra a informação dada por Elias $(2011$, a) de que na figuração cortesã as nuanças de comportamento pelas quais a nobreza se tratava possuía muita importância, com muita semelhança ao sistema de bolsa de valores, não por atribuir valores a coisas e empresas, porém a pessoas.

Parte-se da noção de que o tratamento cortês à pessoa obesa, especificamente na internet, deve ser entendido como passando por um processo civilizador quando se observam os movimentos sociais que buscam dar visibilidade a esse preconceito, que direcionam ações coletivas de cancelamento a pessoas que praticam a gordofobia nos meios digitais e a existência de manuais que inibem o comportamento discriminatório nas redes sociais.

Enquanto Elias (2011, p. 90-91) compreende os poemas e tratados de etiqueta por ele analisados como: "[...] instrumentos diretos de 'condicionamento' ou 'modelação', de adaptação do indivíduo a esses modos de comportamento que a estrutura e situação da sociedade onde vive tornam necessário", vê-se a importância das diretrizes e políticas expressas pelas redes sociais na modelação de comportamentos que não firam a ética. Uma clara política de garantia de dignidade das grandes plataformas, ainda que direcionadas a poucas categorias protegidas, aliado a possibilidade de revolta em massa de usuários na forma de cancelamento conseguem condicionar e moldar aqueles que se expressam nessas redes a conterem ataques verbais a grupos oprimidos. Elias (1993) afirma que houve um processo de longo prazo no Ocidente, até 1880 , em que dominou a formalidade dos costumes, com muitos aspectos do comportamento submetido a regulamentações cada vez mais rígidas e detalhadas, algumas explicitadas em lei, outras marcadas nos costumes.

Como se viu nos manuais de condutas de três grandes redes sociais, o modo de tratamento para algumas minorias já foi formalizado, cabendo na definição de categorias protegidas de ataques, enquanto que para as vítimas de gordofobia espera-se que predomine o bom senso de não ferir sua dignidade e honra como um direito universal. 


\section{Considerações finais}

Nas sociedades de corte, não seguir as regras de etiqueta poderia incorrer em rebaixamento de status, por não enaltecer quem estivesse em alta ou por parecer muito íntimo de alguém em baixa. Hoje, nas interações nos principais meios digitais, comentários preconceituosos que viralizam nas redes, ou seja, que geram muita repercussão em uma cidade ou em todo o globo terrestre podem afetar por completo a vida do autor, causando ostracismo, ameaças e perseguição. Diante da maior conscientização de que ataques a pessoas e grupos de pessoas obesas se configuram em atos de ódio e perseguição, a gordofobia tem recebido atenção de ativistas para barrar esse preconceito nas redes sociais, visto que as interações mediadas pelas tecnologias de comunicação afetam a vida emocional, financeira, social dos indivíduos. Esse modo de interação temse mostrado como um meio de expressar valores e crenças coletivas que nem sempre são manifestados fora do contexto digital com mesmo vigor. Com o maior uso das CMC, aumenta a importância da regulação das emoções. Surge maior necessidade de regras de convivência nos meios digitais, o que permite inferir processos civilizadores ocorrendo na forma de manuais específicos para os meios digitais, como os aqui chamados de netiqueta de cada plataforma. Os manuais de netiqueta ainda não são claros quanto a como se portar diante de todas as minorias, contudo há um consenso de que se deve respeitar os direitos humanos em comentários e discussões. Novos hábitos online vêm se normalizando, pois desrespeito online pode se transformar em transtornos irreversíveis offline. Embora as três redes sociais não façam uso do termo netiqueta, criaram seu manual de boa convivência na qual regulam os comportamentos tolerados e não tolerados. Especificamente sobre a gordofobia, os manuais das redes observadas neste estudo são omissos, pois são explícitos apenas nas proibições com algumas características protegidas, que diferem entre as plataformas. Dada a grande relevância das redes sociais, seus manuais de etiqueta são fonte rica para novas investigações sobre a civilização dos costumes, tanto tendo como alvo pessoas atacadas pela gordofobia quanto outras minorias.

O preconceito contra pessoas obesas tem suscitado maior atenção. Neste artigo se questiona se pessoas alvo de gordofobia se tornarão uma categoria protegida nos manuais das redes sociais ou se sua proteção no mundo online continuará de modo informal e dependente de reação de indignação dos usuários. Embora a gordofobia ainda não esteja contemplada nesses manuais, a leitura dos movimentos pró-direitos humanos permite inferir que a atual configuração caminha para a menor estigmatização. É possível que pessoas obesas demorem mais tempo para serem reconhecidas como categoria a ser protegida por grandes redes sociais como as aqui apontadas. Isto devido a concepção vigente de que se trata de condição que resulta de livre arbítrio, por tanto, de escolhas pessoais. Fato que aumenta a necessidade de debate sobre o tema. 


\section{REFERÊNCIAS}

ABESO. Associação Brasileira para Estudos da Obesidade e Síndrome Metabólica. Diretrizes Brasileiras de Obesidade 2009/2010. Itapevi, SP: AC Farmacêutica, 2009.

BRASIL. Ministério da Saúde. Secretaria de Atenção à Saúde, Departamento de Atenção Básica. Estratégias para o cuidado da pessoa com doença crônica: obesidade. Brasília: Ministério da Saúde, 2014.

COSTA, Célio Juvenal. Reflexões sobre o processo civilizador nos níveis histórico, social e individual. Revista educação e fronteiras on-line, v. 3, p. 149-161, 2013.

ELIAS, Norbert. A sociedade de corte. Rio de Janeiro: Zahar, 2011a.

ELIAS, Norbert. O processo civilizador, volume I: uma história dos costumes. 2 ed. Rio de Janeiro: Zahar, 2011b.

ELIAS, Norbert. O processo civilizador, volume II: formação do estado e civilização. Rio de Janeiro: Zahar, 1993.

FACEBOOK. Padrões da comunidade. 2021. Disponível em: https://www.facebook.com/communitystandards/hate_speech. Acesso em: 3 abr 2021.

GURGEL, Alexandra. Pare de se odiar: porque amar o próprio corpo é um ato revolucionário. Rio de Janeiro: Best Seller, 2018. (recurso digital).

RIBEIRO, Luiz. Carlos. Prefácio. In: GeBARA, Ademir; COSTA, Célio Juvenal; SARAT, Magda. Leituras de Norbert Elias: processo civilizador, educação e fronteiras. SciELO - EDUEM. 2014.

IVO, Mariéllen. Dez dicas de netiqueta na ead. 2017. Unimontes. Disponível em: http://www.ead.unimontes.br/nasala/netiqueta-ea. Acesso em: 7 abr. 2021.

LATNER, Janet D. et al. Greater History of Weight-related Stigmatizing Experience is Associated with Greater Weight Loss in Obesity Treatment. Journal of Health Psychology. Mar;14(2):190-9, 2009.

LIRA, Camila. Gordura é doença? 2019. Azmina. Disponível em: https://azmina.com.br/reportagens/gordura-e-doenca/. Acesso em: 10 abr. 2021.

MARQUEZI, Dagomir. Netiqueta FB: cuidados para tornar mais útil o uso do Facebook. 2012. Matéria incógnita. Disponível em: 
https://www.materiaincognita.com.br/netiqueta-fb-cuidados-para-tornar-maisutil-o-uso-do-facebook/. Acesso em 03 de abril 2021.

MELERO, Maria Beatriz. Gordofobia: por que ainda temos aversão a corpos gordos? 2020. Minha vida. Disponível em: https://www.minhavida.com.br/bemestar/materias/37093-gordofobia-por-que-ainda-temos-aversao-a-corposgordos. Acesso em: 10 abr 2021. Acesso em 03 de abril 2021.

MELO, Vicente Sales; FARIAS, Salomão Alencar; KOVACS, Michelle Helena. Estereótipos e estigmas de obesos em propagandas com apelos de humor. Organizações e sociedade. Salvador, v. 24 , n. 81 , p. 305-324, abr./jun. 2017.

MYERS, David. G. Psicologia social. 10 ed. Porto Alegre: AMGH, 2014.

PAIM, Marina. Bastos.; KOVALESKI, Douglas. Francisco. Análise das diretrizes brasileiras de obesidade: patologização do corpo gordo, abordagem focada na perda de peso e gordofobia. Saude soc., São Paulo , v. 29, n. 1, e190227, 2020. Disponível em http://www.scielo.br/scielo.php?script=sci_arttext\&pid=S010412902020000100310\&lng=pt\&nrm=iso. Acesso em: 2 feb. 2021.

ØSTBYE, Truls et al. Associations between obesity and receipt of screening mammography, Papanicolaou tests, and influenza vaccination: results from the Health and Retirement Study (HRS) and the Asset and Health Dynamics Among the Oldest Old (AHEAD) Study. American journal of public health. v. 95, n. 9, p. 1623-1630, 2005.

PANISSI, Fernando. Veja dicas de 'netiqueta' para usar Twitter e mensagens no celular. G1. 2009. Disponível em: https://g1.globo.com/Noticias/Tecnologia/0,,MUL1228999-6174,00VEJA+DICAS+DE+NETIQUETA+PARA+USAR+TWITTER+E+MENSAGENS+NO+ CELULAR.htmI\# : : text=Objetividade\%3A\%20SMS\%20\%C3\%A9\%20para\%20 ser,quem\%20n\%C3\%A3o\%20usa\%20a\%20rede. Acesso em: 10 abr. 2021.

PIÑEYRO BRUSCHI, Magdalena. Stop gordofobia: y las panzas subversas. Málaga: Zambra y Baladre, 2016.

POULAIN, Jean-Pierre. Sociologia da obesidade. São Paulo: Senac, 2013. RANGEL, Natália Fonseca Abreu. O ativismo gordo em campo: política, identidade e construção de significados. Dissertação (Mestrado em Sociologia Política) - Universidade Federal de Santa Catarina, Florianópolis, 2018.

RECUEIRO, Raquel. Curtir, compartilhar, comentar: trabalho de face, conversação e redes sociais no Facebook. Verso e Reverso, v. 28, n. 68, p. 117-127, 2014. 
RIGO, Luiz Carlos.; SANTOLIN, Cesar Barbosa. Combate à obesidade: uma análise da legislação brasileira. Movimento, Porto Alegre, v.18, n. 2, p. 279296, 2012.

SANCHES, Mariana. O que é a cultura do cancelamento? BBC News Brasil. 2020. Disponível em: https://www.bbc.com/portuguese/geral-53537542 Acesso em: 07 abr 2021.

TOVAR, Virgie. Meu corpo, minhas medidas. Primavera: São Paulo, 2018.

TWITTER. Regras do Twitter e políticas. 2021. Disponível em: https://help.twitter.com/pt/rules-and-policies/hateful-conduct-policy. Acesso em: 22 abr. 2021.

VARTANIAN, Lenny. R.; SHAPROW, Jaquecline. G. Effects of weight stigma on exercise motivation and behavior: A preliminary investigation among collegeaged females. Journal of Health Psychology, v. 13, p. 131-138, 2008.

XIMENES, Eliane, G., XIMENES, Lara; LINS, Daniel. Obesidade. In. Cirurgia da obesidade: um enfoque psicológico. (Org.) Eliane G. Ximenes. São Paulo: Santos editora, 2009.

YOUTUBE. Políticas de discurso de ódio. 2021. Disponível em: https://support.google.com/youtube/answer/2801939 Acesso em: 23 abr. 2021.

Recebido em: 23 de abril de 2021.

Aceito em: 09 de junho de 2021. Publicado em: 30 de junho de 2021. 